\title{
Atypical aetiology in patients hospitalised with community-acquired pneumonia is associated with age, gender and season; a data-analysis on four Dutch cohorts
}

Vivian M. Raeven ${ }^{1,7 \dagger}$, Simone M. C. Spoorenberg ${ }^{1 *+}$, Wim G. Boersma ${ }^{2}$, Ewoudt M. W. van de Garde ${ }^{3,4}$, Suzanne C. Cannegieter ${ }^{5}$, G. P. Paul Voorn ${ }^{6}$, Willem Jan W. Bos ${ }^{1}$, Jim E. van Steenbergen ${ }^{7,8}$, On behalf of the Alkmaar study group and On behalf of the Ovidius study group

\begin{abstract}
Background: Microorganisms causing community-acquired pneumonia (CAP) can be categorised into viral, typical and atypical (Legionella species, Coxiella burnetii, Mycoplasma pneumoniae, and Chlamydia species). Extensive microbiological testing to identify the causative microorganism is not standardly recommended, and empiric treatment does not always cover atypical pathogens. In order to optimize epidemiologic knowledge of CAP and to improve empiric antibiotic choice, we investigated whether atypical microorganisms are associated with a particular season or with the patient characteristics age, gender, or chronic obstructive pulmonary disease (COPD).

Methods: A data-analysis was performed on databases from four prospective studies, which all included adult patients hospitalised with CAP in the Netherlands $(N=980)$. All studies performed extensive microbiological testing.

Results: A main causative agent was identified in 565/980 (57.7 \%) patients. Of these, 117 (20.7\%) were atypical microorganisms. This percentage was $40.4 \%$ (57/141) during the non-respiratory season (week 20 to week 39, early May to early October), and $67.2 \%$ (41/61) for patients under the age of 60 during this season. Factors that were associated with atypical causative agents were: CAP acquired in the non-respiratory season (odds ratio (OR) $4.3,95 \% \mathrm{Cl} 2.68-6.84)$, age <60 year (OR 2.9, $95 \% \mathrm{Cl}$ 1.83-4.66), male gender (OR 1.7, $95 \% \mathrm{Cl}$ 1.06-2.71) and absence of COPD (OR 0.2, $95 \%$ Cl 0.12-0.52).
\end{abstract}

Conclusions: Atypical causative agents in CAP are associated with respectively non-respiratory season, age <60 years, male gender and absence of COPD. Therefore, to maximise its yield, extensive microbiological testing should be considered in patients $<60$ years old who are admitted with CAP from early May to early October.

Trial registration: NCT00471640, NCT00170196 (numbers of original studies).

Keywords: Aetiology, Atypical pathogens, Community-acquired pneumonia, Demography, Pneumonia

\footnotetext{
* Correspondence: s.spoorenberg@antoniusziekenhuis.nl

VM Raeven and SMC Spoorenberg are shared first authors.

${ }^{\dagger}$ Equal contributors

'Department of Internal Medicine, St Antonius Hospital, Nieuwegein, The

Netherlands

Full list of author information is available at the end of the article
} 


\section{Background}

Microorganisms causing community-acquired pneumonia (CAP) can be categorised into viral, typical and atypical microorganisms. Atypical microorganisms are Legionella species, Coxiella (C.) burnetii (Q-fever), Mycoplasma (M.) pneumoniae, and Chlamydia species. In clinical practice, the causative microorganism often remains unidentified since microbiological testing is not standardly performed. However, in patients with low to moderately severe CAP, treatment of first choice allegedly does not cover atypical causative microorganisms [1-3]. To start a pathogendirected treatment, it is important to define specific conditions associated with an increased risk for atypical pathogens.

Cases of CAP are seen throughout the year, but overall incidence rises during winter months [4]. This is due to certain aetiological agents that show seasonal variation: Streptococcus (S.) pneumoniae, Haemophilus influenzae and respiratory viruses occur mainly during winter season $[4,5]$. Of atypical microorganisms, only Legionella (L.) species and C. burnetii show seasonal variation, increasing during summer and during early spring in the lambing season, respectively [6-8]. Numbers of cases of $M$. pneumoniae increase during wintertime, but the incidence is relatively high during summer as well.

Concerning age, incidence of CAP is highest in young children and adults above 65 years old $[9,10]$. S. pneumoniae is the leading causative agent in all age groups. Some atypical pathogens show an atypical age distribution. Cases of L. pneumophila are most commonly seen in patients aged 35 to 50 years old, psittacosis has an increased incidence in patients aged 35 to 55 , and C. burnetii occurs most in men between 30 and 69 years old [11-13].

Furthermore, patients with chronic obstructive pulmonary disease (COPD) or positive smoking status differ in aetiology of CAP $[14,15]$. Consequently, there could be a positive or negative association with these conditions and the prevalence of atypical pathogens.

Microbiological testing can be used to identify the causative microorganism and to distinguish between typical and atypical microorganisms [16]. However, guidelines do not recommend microbiological testing for patients with low to moderately severe CAP, and therefore antibiotic treatment of CAP is usually empirical [1-3]. There is no worldwide consensus on antibiotic management for CAP. The Dutch Working Party on Antibiotic Policy (SWAB) and National Institute for Health and Care Excellence (NICE) guideline recommend amoxicillin as first-choice treatment for hospitalised patients with CAP of low- to moderate severity (pneumonia severity index (PSI) classes $1-4$ or CURB-65 score 0-2) and combination with a macrolide or quinolone in case of severe CAP (PSI class 5 or CURB-65 score $>2$ ) $[2,3]$. The British Thoracic Society (BTS) guideline recommends amoxicillin with macrolide combination therapy in case of moderate to severe CAP [1]. Global differences in preferred antibiotic management can partially be explained by variations in pneumococcal resistance rate between geographical regions and countries [17]. Since $S$. pneumoniae is the leading cause of CAP, the initial therapy should at least cover this microorganism. Nevertheless, beta-lactam antibiotics do not cover atypical microorganisms, leaving these pathogens theoretically uncovered by first-choice treatment for patients with low- to moderately severe CAP.

Since causative microorganisms are not extensively looked for, nor covered by antibiotic treatment in patients with CAP, it would be useful to identify specific circumstances associated with an increased risk for these pathogens as causative agent in CAP. Presence of such characteristics in a patient can then be used to determine optimal treatment. It has been shown that clinical examination, simple laboratory tests and radiographic characteristics cannot distinguish between typical and atypical microorganisms [18-20]. However, to our knowledge there is no scientific literature about seasons as risk factor for atypical pneumonias as a group. In this study, we investigated whether atypical causative microorganisms in patients with CAP are more prominent during a particular season or associated with specific patient characteristics.

\section{Methods}

Study design

A data-analysis was performed on databases from four prospective studies [21-24]. All studies included patients aged 18 years or older who were hospitalised with CAP in the Netherlands and gave written informed consent. Two studies were performed in the St. Antonius Hospital in Nieuwegein, from October 2004 to August 2006 [23] and from November 2007 to September 2010 [21]. The other studies were performed in Medical Center Alkmaar from December 1998 to November 2000 [24] and August 2005 to July 2008 [22]. On all patients, extensive microbiological investigations for pathogen identification was performed such as blood cultures, sputum cultures, urine antigen tests for L. pneumophila serogroup 1 and S. pneumoniae, and paired complement fixation test [21] or ELISA test [22-24] for M. pneumoniae, C. burnetii, Chlamydia species and the viruses adenovirus, influenza virus $A$ and B, parainfluenza virus 1,2 and 3 , and the respiratory syncytial virus. A four-fold increase in antibody titre was considered as positive. Two studies performed polymerase chain reaction (PCR) for atypical pathogens and respiratory viruses $[21,23]$. Further details are described elsewhere [21-24].

The following data were used from these datasets: date of admission, age, gender, antibiotics treatment before hospitalisation, duration of antibiotic therapy, presence of COPD, smoking status, whether the patient was living 
in a nursing home, PSI at admission, mortality within 30 days and main causative pathogen.

\section{Definition of season and outcome}

Date of admission was classified to be either in the respiratory season (week 40 to 19; from early October to early May) or the non-respiratory season (week 20 to 39). This classification was chosen because we expected atypical microorganisms to be associated with non-respiratory season, considering their known seasonal variation, and because the format is easy to use in daily practice. Main causative agents were grouped in three categories: 'atypical', 'other' and 'unknown'. Data-analysis was performed using 'atypical vs. other pathogen' as outcome. The category 'atypical' consisted of Legionella species, M. pneumoniae, Chlamydia species and C. burnetii as causative agents. The category 'other' consisted of all other bacterial and viral causative microorganisms. The category 'unknown' consisted of patients with CAP in whom the causative agent remained unidentified after microbiological investigation. These unidentified cases were excluded from the primary analysis since it is unknown whether the proportion of atypical causative pathogens is lower, higher or equal to the identified group.

\section{Statistical analysis}

Data management and statistical analysis were performed using IBM SPSS Statistics for Windows, Version 22.0. Categorical variables were summarized as percentages, non-categorical variables were summarized as mean (standard deviation) or median (interquartile range) as appropriate. Differences between categories were observed by means of Pearson's chi-squared test for parametrical variables, versus Kruskall-Wallis test for non-parametrical samples.

To determine an age cut-off for further analyses, the percentage of atypical pathogens in patients younger and older than all ages between 40 and 70 years old was calculated. A cut-off point at age 60 was chosen based on these results.

Univariable logistic regression analysis was performed for the following parameters: respiratory season, age $<60$, male gender, presence of COPD and smoking. Variables significant in univariable analysis and variables expected to be associated with atypical causative agents were selected for multivariable analysis. Potential interactions between age and presence of COPD were investigated using interaction terms in logistic regression analysis. Smoking was excluded from multivariable analysis due to 243 missing values.

Several sensitivity analyses were performed. In the first sensitivity analyses viral pathogens were excluded. The second analysis indicated all unknown pathogens as not atypical; the third analysis indicated all unknown pathogens as atypical. A fourth analysis excluded Legionella CAPs in
1999 and C. burnetii CAPs in 2009, based on the outbreaks in those years of inclusion $[6,8]$. Another sensitivity analysis excluded all Legionella CAPs. Also, an analysis was performed including exclusively the two studies that performed PCR to detect atypical pathogens and respiratory viruses [21, 23]. Last, extra analyses were performed excluding patients who were treated with antibiotics before hospitalisation and patients with a severe CAP (PSI score V), respectively.

\section{Results}

\section{Aetiology and baseline characteristics}

In total 980 patients were included in the analysis, including all patients from the original four databases. Median age was 67 years (IQR 52-78) and $57.2 \%$ was male. These distributions did not significantly differ between the four studies. Table 1 shows all baseline characteristics of the included studies. In 565/980 (57.7 \%) patients the causative microorganism of CAP was identified. Atypical microorganisms were causative pathogens in $117 / 980$ patients (11.9 \%); 35.9 \% were cases with Legionella species (42/117), $26.5 \%$ with M. pneumoniae (31/117), $23.9 \%$ with C. burnetii (28/117), and $13.7 \%$ with Chlamydia species (16/117). Figure 1 shows the number of every atypical pathogen per year of inclusion.

Further analyses were performed on the three aetiologic categories (atypical, other pathogen and unknown). Baseline characteristics of the patients in these three categories are shown in Table 2. The variables age, COPD, smoking, nursing home resident and severity of pneumonia (according to PSI class) differed significantly between the three categories.

\section{Seasonal and age variations}

Of all identified microorganisms, the percentage of atypical pathogens was $20.7 \%$ (117/565). Forty percent (40.4\%, $n=57$ ) of CAP cases during the non-respiratory season were atypical, compared to $14.2 \%(n=60)$ during the respiratory season (Fig. 2a).

For CAP in patients under 60 years of age, $33.8 \%$ $(n=74)$ was caused by an atypical pathogen, compared to $12.4 \%(n=43)$ for patients $\geq 60$ years (Fig. $2 b)$.

Combining seasonal effect and age, incidence of CAP caused by atypical microorganisms during the nonrespiratory season was $67.2 \%(n=41)$ in patients younger than 60 years. This percentage was $20 \%$ in patients $\geq 60$ years $(n=16$, Fig. $2 \mathrm{c}$ and d).

\section{Logistic regression analysis}

In univariable and multivariable logistic regression analysis, non-respiratory season, age $<60$, and absence of COPD were significantly associated with an atypical causative agent. No significant interaction was found between age and COPD (p:0.61). Male gender was nearly significant 
Table 1 Baseline characteristics and aetiology per study of all 980 patients

\begin{tabular}{|c|c|c|c|c|c|}
\hline & $\begin{array}{l}\text { All patients } \\
(n=980)\end{array}$ & $\begin{array}{l}\text { Meijvis [21] } \\
(n=304)\end{array}$ & $\begin{array}{l}\text { Endeman [23] } \\
(n=201)\end{array}$ & $\begin{array}{l}\text { Snijders [22] } \\
(n=213)\end{array}$ & $\begin{array}{l}\text { Vd Eerden [24] } \\
(n=262)\end{array}$ \\
\hline Demographic characteristics & No. & No. & No. & No. & No. \\
\hline Male gender (\%) & $561(57.2)$ & $171(56.3)$ & $124(61.7)$ & $124(58.2)$ & $142(54.2)$ \\
\hline Age in years, median (IQR) & $67(52-78)$ & $66.5(51-79)$ & $68(51.5-76)$ & $65(51.5-80)$ & $68(52-78)$ \\
\hline COPD (\%) & $236(24.2)$ & $34(11.2)$ & $64(31.8)$ & $43(20.3)$ & $95(36.7)$ \\
\hline Smoking (\%) & $211(28.6)$ & $81(29.2)$ & a & $56(26.8)$ & $74(29.5)$ \\
\hline Nursing home resident (\%) & $29(3.0)$ & $16(5.3)$ & $3(1.5)$ & $4(1.9)$ & $6(2.3)$ \\
\hline PSI class IV or V (\%) & $435(44.4)$ & $142(46.7)$ & $84(41.8)$ & $94(44.1)$ & $115(43.9)$ \\
\hline 30-Day mortality (\%) & $67(6.8)$ & $18(5.9)$ & $8(4.0)$ & $12(5.6)$ & $29(11.1)$ \\
\hline \multicolumn{6}{|l|}{ Aetiology (\%) } \\
\hline Streptococcus pneumoniae & $282(28.8)$ & $64(21.1)$ & $60(29.9)$ & $78(36.6)$ & $80(30.5)$ \\
\hline Haemophilus influenzae & $55(5.6)$ & $9(3.0)$ & $18(9.0)$ & $7(3.3)$ & $21(8.0)$ \\
\hline Legionella species & $42(4.3)$ & $12(3.9)$ & $8(4.0)$ & $8(3.8)$ & $14(5.3)$ \\
\hline Mycoplasma pneumoniae & $31(3.2)$ & $5(1.6)$ & $4(2.0)$ & $13(6.1)$ & $9(3.4)$ \\
\hline Coxiella burnetii & $28(2.9)$ & $27(8.9)$ & $1(0.5)$ & $0(0)$ & $0(0)$ \\
\hline Influenza A/B virus & $25(2.6)$ & $7(2.3)$ & $6(3.0)$ & $3(1.4)$ & $9(3.4)$ \\
\hline Staphylococcus aureus & $21(2.1)$ & $3(1.0)$ & $6(3.0)$ & $2(0.9)$ & $10(3.8)$ \\
\hline Chlamydia species & $16(1.6)$ & $14(4.6)$ & $2(1.0)$ & $0(0)$ & $0(0)$ \\
\hline Adenovirus & $6(0.6)$ & $1(0.3)$ & $1(0.5)$ & $2(0.9)$ & $2(0.8)$ \\
\hline Other bacteria & $38(3.9)$ & $15(4.9)$ & $12(6.0)$ & $5(2.3)$ & $6(2.3)$ \\
\hline Other viruses & $21(2.1)$ & $11(3.6)$ & $9(4.5)$ & $0(0)$ & $1(0.4)$ \\
\hline Unidentified & $415(42.3)$ & $136(44.7)$ & $74(36.8)$ & $95(44.6)$ & $110(42.0)$ \\
\hline
\end{tabular}

Results are given as number and percentage, unless mentioned otherwise

Abbreviations: COPD chronic obstructive pulmonary disease, ICU intensive care unit, IQR interquartile range, $P S I$ pneumonia severity index

${ }^{a}$ Indicates all missing values

in univariable analysis (OR 1.5, $95 \% 1.00-2.33$, p:0.052), and significant in multivariable analysis (OR 1.7, $95 \%$ 1.06-2.71). Too little patients were living in a nursing home to include this variable in the analyses. Table 3 shows all ORs and $95 \%$ CIs.

\section{Sensitivity analyses}

When viral pathogens were excluded from multivariate analysis, odds ratios did not essentially change (see Table 4). Similar results were found when all unknown pathogens were indicated as not atypical. When all unknown

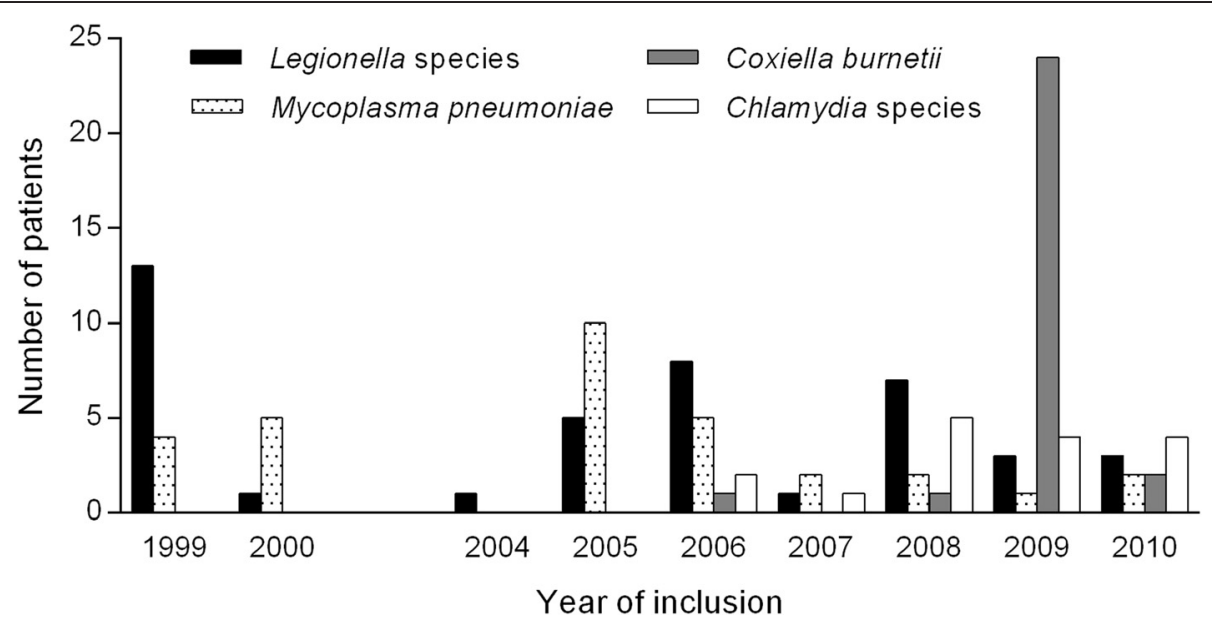

Fig. 1 Number of atypical pathogens per year of inclusion 
Table 2 Demographic characteristics and outcome of 980 patients hospitalised with community-acquired pneumonia

\begin{tabular}{lllll}
\hline & $\begin{array}{l}\text { Total } \\
(n=980)\end{array}$ & $\begin{array}{l}\text { Atypical } \\
(n=117)\end{array}$ & $\begin{array}{l}\text { Other pathogen } \\
(n=448)\end{array}$ & $\begin{array}{l}\text { Unknown } \\
(n=415)\end{array}$ \\
\hline Male gender (\%) & $561(57.2)$ & $77(65.8)$ & $250(55.8)$ & $234(56.4)$ \\
Age in years (IQR) & $67(52-78)$ & $52(41.5-67)$ & $68(54-78)$ & $69(55-80)^{*}$ \\
COPD (\%) & $236(24.1)$ & $9(7.7)$ & $135(30.3)$ & $92(22.3)^{*}$ \\
Smoking (\%) & $211(28.6)$ & $38(40.4)$ & $93(29.3)$ & $80(24.5)^{*}$ \\
Nursing home resident (\%) & $29(3.0)$ & $0(0.0)$ & $8(1.8)$ & $21(5.1)^{*}$ \\
PSI class IV or V (\%) & $435(44.4)$ & $38(32.5)$ & $219(48.9)$ & $178(42.9)^{*}$ \\
30-Day mortality (\%) & $67(6.8)$ & $6(5.1)$ & $33(7.4)$ & $28(6.7)$ \\
\hline
\end{tabular}

Results are given as number (percentage) or median (interquartile range)

Abbreviations: COPD chronic obstructive pulmonary disease, ICU intensive care unit, IQR interquartile range, $P S /$ pneumonia severity index

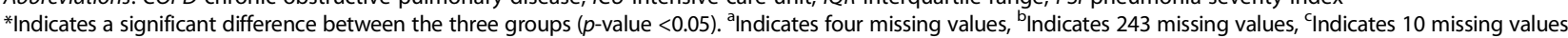

pathogens were indicated as atypical, the OR for nonrespiratory season remained significantly elevated, ORs for age $<60$ and male gender remained elevated but became non-significant. All ORs can be found in Table 4.

The sensitivity analysis excluding all Legionella cases in 1999 and C. burnetii cases in 2009 showed similar results (see Table 5). The analyses excluding all Legionella CAPs and the two studies that did not use PCR methods all showed non-respiratory season and age $<60$ to be even stronger predictors for atypical CAP (see Table 5).

Excluding PSI class 5 resulted in remaining significance for non-respiratory season, age $<60$ and COPD. The OR for male gender was higher than 1 (1.5), but not statistically significant. Non-respiratory season, age $<60$ and COPD all remained significant predictors for an atypical causative agent in the analysis excluding patients

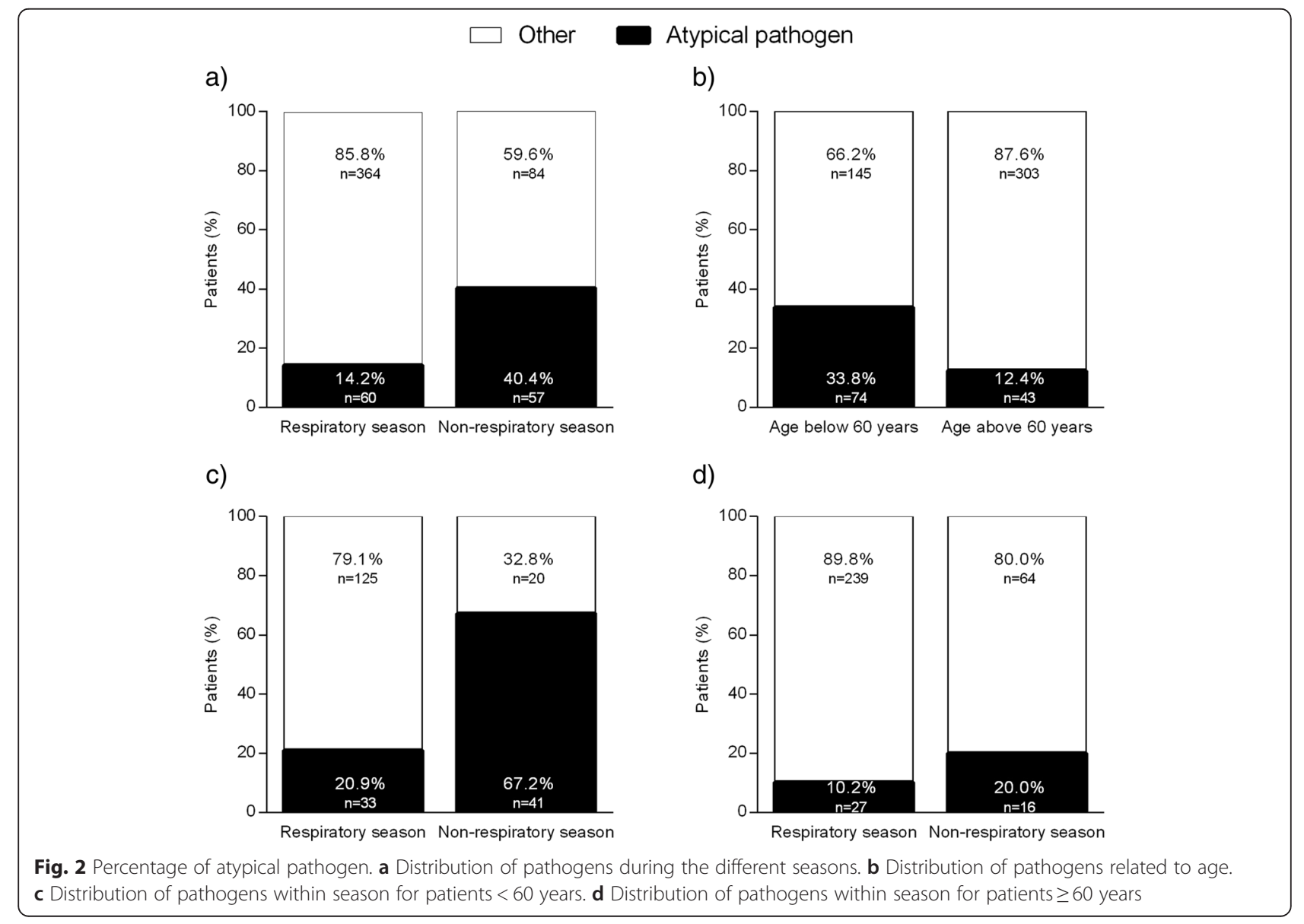


Table 3 Univariable and multivariable logistic regression analysis of atypical versus other pathogens with cases with unknown aetiology excluded

\begin{tabular}{|c|c|c|c|c|}
\hline \multirow[b]{2}{*}{ Parameter } & \multicolumn{2}{|c|}{ Univariable analysis } & \multicolumn{2}{|c|}{ Multivariable analysis } \\
\hline & OR & $95 \% \mathrm{Cl}$ & OR & $95 \% \mathrm{Cl}$ \\
\hline Non-respiratory season & 4.1 & $2.67-6.35^{* *}$ & 4.3 & $2.68-6.84^{* *}$ \\
\hline Age $<60$ years & 3.6 & $2.35-5.50^{* *}$ & 2.9 & $1.83-4.66^{* *}$ \\
\hline Male gender & 1.5 & $1.00-2.33$ & 1.7 & $1.06-2.71^{*}$ \\
\hline $\mathrm{COPD}^{\mathrm{a}}$ & 0.2 & $0.09-0.39^{* *}$ & 0.2 & $0.12-0.52^{* *}$ \\
\hline Smoking ${ }^{b}$ & 1.6 & $1.01-2.64^{*}$ & & Excluded \\
\hline
\end{tabular}

Abbreviations: OR odds ratio, $\mathrm{Cl}$ confidence interval, COPD chronic obstructive pulmonary disease

*Indicates a $p$-value $<0.05 ; * *$ Indicates a $p$-value $<0.001$

a Indicates four missing values; ${ }^{b}$ Indicates 243 missing values

who were treated with antibiotics before hospitalisation. Results from the analysis excluding respectively patients with PSI class 5 and patients who used antibiotics before hospitalisation can be found in Additional file 1: Table S1.

\section{Discussion}

In this analysis of 980 patients hospitalised with CAP in whom extensive microbiological testing was performed, we found non-respiratory season, age $<60$, male gender and absence of COPD to be associated with an atypical microorganism as causative agent. The proportion of CAP cases caused by atypical microorganisms was much higher during the non-respiratory season than in respiratory season ( $40.4 \%$ vs. $14.2 \%$ ). This proportion was even higher in patients below 60 years in non-respiratory season $(67.2 \%)$.

To our knowledge, there is no scientific literature about season as a risk factor for atypical pneumonias. Factors that indicate an association with pneumonia caused by this group of pathogens can optimize epidemiologic knowledge. Since none of the atypical pathogens are theoretically covered by empiric antibiotic treatment in non-severe pneumonia, this knowledge can possibly reduce treatment failure in this pathogen group. In literature, there is controversy regarding the need to use antibiotics covering atypical pathogens in the initial treatment of patients with CAP. Recent studies show no differences in clinical efficiency, nor differences in mortality between antibiotic treatment with and without atypical coverage, meaning that these atypical infections might resolve spontaneously under inadequate antibiotic therapy [25-27]. Mostly, this relates to the comparison of quinolone monotherapy with beta-lactam monotherapy. However, these studies describe empirical treatment of CAP, regularly without extensive microbiological testing and therefore the causing pathogen is often not identified [25, 26]. It is unknown if outcome of CAPs caused by an atypical pathogen is improved if adequate antibiotic coverage is started immediately on admission. In the CAP-START study, beta-lactam therapy was non-inferior to beta-lactam plus macrolide, but $8.1 \%$ of the patients who were empirically treated with betalactams did deviate from the study protocol due to the need for atypical coverage. Overall, $38.7 \%$ of the patients in the beta-lactam group received atypical antibiotic coverage during admission [27].

For observing seasonal variations, we used the format of calendar respiratory season vs. non-respiratory season (from early May to early October). This format was used because we expected the proportion of atypical microorganisms to be elevated in the non-respiratory season. Furthermore, the format non-respiratory season is easy to use in daily practice. The use of other formats such as astronomical seasons or influenza-epidemic could provide additional information on the epidemiology of CAP in the Netherlands. We performed additional analyses using these formats, showing the highest percentage of atypical CAPs during summer and lowest incidence during winter (data not shown). Using respiratory vs. nonrespiratory season showed highest predictive value.

The main limitation of this study is the fact that the prevalence of atypical microorganisms could have been over- or underestimated due to several reasons. First, it is impossible to assess the proportion of atypical causative agents in the unidentified group. It is suggested that the majority of unidentified CAP cases is caused by $S$. pneumoniae, but it is unknown whether the proportion of atypical causative pathogens is lower, higher or equal to the identified group [28]. As only the distribution in the group of identified cases is evident, data-analysis was

Table 4 Three multivariable logistic regression sensitivity analyses: 1) Excluding viral pathogens; 2) Cases with unknown aetiology being indicated as not atypical; and 3) Cases with unknown aetiology being indicated as atypical

\begin{tabular}{|c|c|c|c|c|c|c|}
\hline \multirow[b]{2}{*}{ Parameter } & \multicolumn{2}{|c|}{ 1) Atypical vs. other (viral cases excluded) } & \multicolumn{2}{|c|}{ 2) Atypical vs. other and unknown } & \multicolumn{2}{|c|}{ 3) Atypical and unknown vs. other } \\
\hline & $\mathrm{OR}$ & $95 \% \mathrm{Cl}$ & $\mathrm{OR}$ & $95 \% \mathrm{Cl}$ & $\mathrm{OR}$ & $95 \% \mathrm{Cl}$ \\
\hline Non-respiratory season & 4.2 & $2.58-6.72^{* *}$ & 3.0 & $1.95-4.47^{* *}$ & 2.0 & $1.47-2.76^{* *}$ \\
\hline Age $<60$ years & 2.7 & $1.69-4.36^{* *}$ & 3.0 & $1.97-4.59^{* *}$ & 1.0 & $0.75-1.35$ \\
\hline Male gender & 1.7 & $1.09-2.81^{*}$ & 1.6 & $1.02-2.41^{*}$ & 1.2 & $0.91-1.56$ \\
\hline $\mathrm{COPD}^{\mathrm{a}}$ & 0.2 & $0.11-0.48^{* *}$ & 0.3 & $0.15-0.65^{*}$ & 0.5 & $0.37-0.70^{* *}$ \\
\hline
\end{tabular}

Abbreviations: $O R$ odds ratio, $\mathrm{Cl}$ confidence interval, $C O P D$ chronic obstructive pulmonary disease

*Indicates a $p$-value $<0.05$; **Indicates a $p$-value $<0.001$

andicates four missing values 
Table 5 Two multivariable logistic regression sensitivity analyses with: 1) Outbreaks excluded; 2) All Legionella cases excluded; 3) Only two studies that used PCR methods

\begin{tabular}{|c|c|c|c|c|c|c|}
\hline & \multicolumn{2}{|c|}{ 1) Outbreaks excluded } & \multicolumn{2}{|c|}{ 2) Legionella cases excluded } & \multicolumn{2}{|c|}{ 3) PCR based studies } \\
\hline & OR & $95 \% \mathrm{Cl}$ & OR & $95 \% \mathrm{Cl}$ & $\mathrm{OR}$ & $95 \% \mathrm{Cl}$ \\
\hline Non-respiratory season & 4.2 & $2.38-7.30^{* *}$ & 5.4 & $3.02-9.64^{* *}$ & 8.3 & $4.35-15.80^{* *}$ \\
\hline Age $<60$ years & 4.2 & $2.38-7.30^{* *}$ & 6.1 & $3.24-11.55^{* *}$ & 3.7 & $1.93-7.06^{* *}$ \\
\hline Male gender & 1.8 & $1.02-3.05^{*}$ & 1.7 & $0.94-3.00$ & 1.4 & $0.74-2.68$ \\
\hline $\mathrm{COPD}^{\mathrm{a}}$ & 0.2 & $0.08-0.54^{*}$ & 0.1 & $0.04-0.51^{*}$ & 0.2 & $0.07-0.71^{*}$ \\
\hline
\end{tabular}

Abbreviations: $O R$ odds ratio, $C l$ confidence interval, COPD chronic obstructive pulmonary disease

*Indicates a $p$-value $<0.05$; * Indicates a $p$-value $<0.001$

andicates four missing values

performed using 'atypical vs. other proven causative agent' as outcome, hereby excluding the unidentified cases. This could have led to either over- or underestimation. However, the sensitivity analyses defining unidentified cases as not atypical showed small differences. Since it is debatable to appoint viral pathogens as main CAP causing microorganism, we performed an analysis excluding viral cases. This analysis showed similar results for all used variables.

A second limitation is that all CAP severities were included in the analysis. Treatment regimens differ worldwide, but it is usually recommended to cover atypical causative microorganisms in patients with severe CAP. Because we aimed to identify patient characteristics associated with atypical causative microorganisms in all cases of CAP, severe CAPs were not excluded from analyses. To validate our results for patients with low-to moderately severe CAP, the extra analysis was performed excluding patients with PSI class 5 , which showed similar results.

Third, we used data from four different studies, in which not exactly the same microbiological tests were performed. Two studies did not use PCR, whereas this test is known to be more sensitive for diagnosing atypical bacteria compared to conventional testing [29]. In the studies that performed PCR, $17.4 \%$ of atypical microorganisms was identified with PCR alone. It is therefore possible that atypical microorganisms were underrepresented in the studies without PCR $[22,24]$. Including only the two studies that used PCR methods showed elevated ORs for non-respiratory season and age $<60$. All four studies did perform two-fold serological testing for antibodies against atypical microorganisms, but these tests have shortcomings in sensitivity and specificity in diagnosing atypical microorganisms [30]. Pneumococcal antigen testing has not been consequently performed in all studies. Antigen detection performed in non-urine specimens may increase the diagnostic yield of pneumococcal infections, but was performed in only two studies [22, 24, 31].

Finally, some patients had already been treated with antibiotics before admission. Performing PCR and serology for atypical pathogens while using only cultures for other aetiology could have led to an overestimation of atypical pathogens, since cultures are influenced by antibiotic pretreatment whereas serology and PCR are not. We performed an analysis excluding all patients who were treated with antibiotics before hospital admission, which did not change the results.

A strength of this study is the large number of identified atypical pathogens, enabling us to identify significant predictors for CAP caused by atypical pathogens. Furthermore, extensive microbiological testing was performed for every patient, hereby providing a detailed impression on epidemiology of CAP. Our results are applicable for hospitalised patients, but might be extrapolated to general practice. Several studies have shown that microbiological aetiology of CAP differs between hospital and ambulatory setting, with a higher incidence of atypical pathogens and respiratory viruses in mild cases of CAP in ambulatory setting $[10,32,33]$. This suggests that for general practitioners respiratory season, gender and age might be adequate indicators to identify pneumonia patients in whom microbiologic testing needs to be considered or in whom antibiotic treatment (if required) should not be selected purely on the existing first choice regimen. Further research is needed to explore whether there are differences in clinical outcome for patients under the age of 60 presenting during non-respiratory season when treated with antibiotics with and without immediate atypical coverage. With regard to the results presented in this study, we would recommend to perform extensive microbiological testing in male patients, younger than 60 years old, who are admitted with CAP during non-respiratory season in order to optimise epidemiologic knowledge.

\section{Conclusions}

Atypical causative agents in CAP are associated with respectively non-respiratory season, age $<60$ years, male gender and absence of COPD. Therefore, extensive microbiological testing should be considered in patients $<60$ years old who are admitted with CAP from early May to early October. 


\section{Additional file}

Additional file 1: Table S1. Extra multivariable logistic regression analyses, excluding: 1) Pneumonia severity index class $V_{\text {; }}$ and 2) Patients who were treated with antibiotics before hospitalisation. (DOC $37 \mathrm{~kb}$ )

\section{Abbreviations}

$95 \%$ Cl, 95 \% confidence interval; BTS, British Thoracic Society; C. Burnetii, Coxiella burnetii; CAP, community-acquired pneumonia; COPD, chronic obstructive pulmonary disease; ELISA, enzyme-linked immuno sorbent assay; L. pneumophila, Legionella pneumophila; M. pneumoniae, Mycoplasma pneumoniae; NICE, National Institute for Health and Care Excellence; OR, odds ratio; PCR, polymerase chain reaction; $P S I$, pneumonia severity index; $S$. pneumoniae, Streptococcus pneumoniae; SWAB, Dutch Working Party on Antibiotic Policy

\section{Acknowledgements}

We thank all members of the Alkmaar and Ovidius study groups. The Alkmaar study group consists of Wim G Boersma, Menno M van der Eerden and Dominic Snijders. The Ovidius study group consists of Douwe H Biesma, Willem Jan W Bos, Henrik Endeman, Ewoudt MW van de Garde, Jan C Grutters, Hans Hardeman, Rik Heijligenberg, Sabine CA Meijvis, Hilde H Remmelts, Ger T Rijkers, Heleen van Velzen-Blad, and GP (Paul) Voorn.

\section{Funding}

There were no funding sources for this study.

\section{Availability of data and materials}

The readers interested in using the data of the four trials may contact W.J.W. Bos at the St. Antonius Hospital, Koekoekslaan 1, 3430 EM, P.O. Box 2500, Nieuwegein, The Netherlands. Confidential patient data will not be shared.

\section{Authors' contributions}

VR: contributed to conception of design of study, analysis of data and interpretation of results, and drafting the manuscript; SS: analysis of data and interpretation of results, and drafting the manuscript; WGB: contributed to acquisition of data, and critical review of manuscript; EG: contributed to interpretation of data and critical review of manuscript; SC: contributed to analysis of data, interpretation of results, and critical review of the manuscript: PV: contributed to cleaning of data, acquisition of data, and critical review of the manuscript; WJB contributed to conception and design of study, acquisition of data, analysis of data and interpretation of results, and critical review of the manuscript; JS: contributed to conception and design of study, interpretation of results, and critical review of the manuscript. All authors read and approved the final manuscript.

\section{Competing interests}

There were no competing interests. Outside this work, Willem Jan W Bos received a grant from the St Antonius Research Fund via an earmarked donation for research on CAP. Ewoudt MW van de Garde received a research grant from GlaxoSmithKline for a project on aetiology of CAP.

\section{Consent for publication}

Not applicable.

\section{Ethics approval and consent to participate}

The trials that were used in this analysis received ethical approval provided by the local medical ethics committees of the St. Antonius Hospital [21, 23] and the Medical Center Alkmaar [22, 24], respectively. All patients provided written informed consent.

\section{Author details}

'Department of Internal Medicine, St Antonius Hospital, Nieuwegein, The Netherlands. ${ }^{2}$ Department of Pulmonary Medicine, Medical Centre Alkmaar, Alkmaar, The Netherlands. ${ }^{3}$ Department of Clinical Pharmacy, St. Antonius Hospital, Nieuwegein, The Netherlands. ${ }^{4}$ Division of Pharmacoepidemiology and Clinical Pharmacology, Faculty of Science, Utrecht University, Utrecht, The Netherlands. ${ }^{5}$ Department of Clinical Epidemiology, Leiden University Medical Centre, Leiden, The Netherlands. ${ }^{6}$ Department of Medical Microbiology and Immunology, St. Antonius Hospital, Nieuwegein, The
Netherlands. ${ }^{7}$ Centre for Infectious Disease Control, National Institute for Public Health and the Environment, Bilthoven, The Netherlands. ${ }^{8}$ Centre of Infectious Diseases, Leiden University Medical Centre, Leiden, The Netherlands.

Received: 21 February 2016 Accepted: 7 June 2016

Published online: 17 June 2016

\section{References}

1. Lim WS, Baudouin SV, George RC, Hill AT, Jamieson C, Le Jeune I, et al. BTS guidelines for the management of community acquired pneumonia in adults: update 2009. Thorax. 2009;64 Suppl 3:1-55. iii.

2. Wiersinga W, Bonten M, Boersma W, Jonkers R, Aleva R, Kullberg B, et al. SWAB/NVALT (Dutch Working Party on Antibiotic Policy and Dutch Association of Chest Physicians) guidelines on the management of community-acquired pneumonia in adults. Neth J Med. 2012;70:90-101.

3. National Clinical Guideline Centre (UK). Pneumonia: Diagnosis and Management of Community- and Hospital-Acquired Pneumonia in Adults. 2014. https://www.nice.org.uk/guidance/cg191. Accessed 12 May 2015.

4. Dowell SF, Whitney CG, Wright C, Rose Jr CE, Schuchat A. Seasonal patterns of invasive pneumococcal disease. Emerg Infect Dis. 2003;9:574.

5. Schwarzmann SW, Adler JL, Sullivan RJ, Marine WM. Bacterial pneumonia during the Hong Kong influenza epidemic of 1968-1969: experience in a city-county hospital. Arch Intern Med. 1971;127:1037-41.

6. Den Boer J, Nijhof J, Friesema I. Risk factors for sporadic communityacquired Legionnaires' disease. A 3-year national case-control study. Public Health. 2006;120:566-71.

7. Brandsema P, Euser S, Karagiannis I, Den Boer J, van der Hoek W. Summer increase of Legionnaires' disease 2010 in The Netherlands associated with weather conditions and implications for source finding. Epidemiol Infect. 2014:142:2360-71.

8. Roest HJ, van Steenbergen J, Wijkmans C, van Duijnhoven Y, Stenvers O, Oomen T, et al. Q-koorts in 2008 in Nederland en de verwachting voor 2009. Tijdschr Diergeneeskd. 2009;134:300

9. Brandsema P, Dijkstra F, Euser S, van Gageldonk-Lafeber A, de Lange M, Meijer A, et al. Jaarrapportage surveillance respiratoire infectieziekten 2012. National Institute for Public Health and the Environment. 2013. http://www. rivm.nl/dsresource?objectid=rivmp:228955\&type=org\&disposition= inline\&ns_nc=1. Accessed 10 May 2015.

10. Marrie TJ, Poulin-Costello M, Beecroft MD, Herman-Gnjidic Z. Etiology of community-acquired pneumonia treated in an ambulatory setting. Respir Med. 2005:99:60-5.

11. Marston BJ, Lipman HB, Breiman RF. Surveillance for Legionnaires' disease: risk factors for morbidity and mortality. Arch Intern Med. 1994;154:2417-22.

12. Yung AP, Grayson ML. Psittacosis-a review of 135 cases. Med J Aust. 1988; 148:228-33.

13. Raoult D, Tissot-Dupont H, Foucault C, Gouvernet J, Fournier PE, Bernit E, et al. Q fever 1985-1998: clinical and epidemiologic features of 1,383 infections. Medicine. 2000;79:109-23.

14. Almirall J, Blanquer J, Bello S. Community-acquired pneumonia among smokers. Arch Bronconeumol. 2014:50:250-4.

15. Liapikou A, Polverino E, Ewig S, Cillóniz C, Marcos MA, Mensa J, et al. Severity and outcomes of hospitalised community-acquired pneumonia in COPD patients. Eur Respir J. 2012;39:855-61.

16. Van der Eerden M, Vlaspolder F, De Graaff $C$, Groot $T$, Jansen H, Boersma W. Value of intensive diagnostic microbiological investigation in low-and highrisk patients with community-acquired pneumonia. European J Clin Microbiol Infect Dis. 2005;24:241-9.

17. Torres A, Ausina V. Empirical treatment of nonsevere community-acquired pneumonia: still a difficult issue. Eur Respir J. 1995;8:1996-8.

18. File Jr TM. Community-acquired pneumonia. Lancet. 2003;362:1991-2001.

19. Huijts SM, Boersma W, Grobbee D, Gruber W, Jansen K, Kluytmans J, et al. Predicting pneumococcal community-acquired pneumonia in the emergency department. Clin Microbiol Infec. 2014;20:1316-22.

20. Boersma WG, Daniels J, Löwenberg A, Boeve W, van de Jagt EJ. Reliability of radiographic findings and the relation to etiologic agents in communityacquired pneumonia. Respir Med. 2006;100:926-32.

21. Meijvis SC, Hardeman H, Remmelts HH, Heijligenberg R, Rijkers GT, van Velzen-Blad $H$, et al. Dexamethasone and length of hospital stay in patients with community-acquired pneumonia: a randomised, double-blind, placebo-controlled trial. Lancet. 2011;377:2023-30. 
22. Snijders D, Daniels JM, de Graaff CS, van der Werf TS, Boersma WG. Efficacy of corticosteroids in community-acquired pneumonia: a randomized double-blinded clinical trial. Am J Respir Crit Care Med. 2010;181:975-82.

23. Endeman $H$, Schelfhout V, Paul Voorn G, van Velzen-Blad H, Grutters JC, Biesma DH. Clinical features predicting failure of pathogen identification in patients with community acquired pneumonia. Scand J Infect Dis. 2008;40: 715-20.

24. van der Eerden MM, Vlaspolder F, de Graaff CS, Groot T, Bronsveld W, Jansen HM, et al. Comparison between pathogen directed antibiotic treatment and empirical broad spectrum antibiotic treatment in patients with community acquired pneumonia: a prospective randomised study. Thorax. 2005;60:672-8.

25. Eliakim-Raz N, Robenshtok E, Shefet D, Gafter-Gvili A, Vidal L, Paul M, et al. Empiric antibiotic coverage of atypical pathogens for community-acquired pneumonia in hospitalized adults. Cochrane Database Syst Rev. 2012;9.

26. Mills GD, Oehley MR, Arrol B. Effectiveness of beta lactam antibiotics compared with antibiotics active against atypical pathogens in non-severe community acquired pneumonia: meta-analysis. BMJ. 2005;330:456.

27. Postma DF, van Werkhoven $\mathrm{CH}$, van Elden L, Thijsen SF, Hoepelman Al, Kluytmans JA, et al. Antibiotic treatment strategies for community-acquired pneumonia in adults. N Engl J Med. 2015;372:1312-23.

28. Johansson N, Kalin M, Tiveljung-Lindell A, Giske CG, Hedlund J. Etiology of community-acquired pneumonia: increased microbiological yield with new diagnostic methods. Clin Infect Dis. 2010;50:202-9.

29. Templeton KE, Scheltinga SA, van den Eeden WC, Graffelman AW, van den Broek PJ, Claas EC. Improved diagnosis of the etiology of communityacquired pneumonia with real-time polymerase chain reaction. Clin Infect Dis. 2005;41:345-51.

30. Schneeberger P, Dorigo-Zetsma JW, Zee AVD, Bon MV, Opstal JV. Diagnosis of atypical pathogens in patients hospitalized with community-acquired respiratory infection. Scand J Infect Dis. 2004;36:269-73.

31. Boersma WG, Löwenberg A, Holloway Y, Kuttschrutter H, Snijder JA, Koeter $\mathrm{GH}$. Pneumococcal capsular antigen detection and pneumococcal serology in patients with community acquired pneumonia. Thorax. 1991;46:902-6.

32. Cunha B. The atypical pneumonias: clinical diagnosis and importance. Clin Microbiol Infec. 2006;12:12-24.

33. Graffelman AW, Knuistingh Neven A, le Cessie S, Kroes AC, Springer MP, van den Broek PJ. Pathogens involved in lower respiratory tract infections in general practice. Br J Gen Pract. 2004;54:15-9.

\section{Submit your next manuscript to BioMed Central and we will help you at every step:}

- We accept pre-submission inquiries

- Our selector tool helps you to find the most relevant journal

- We provide round the clock customer support

- Convenient online submission

- Thorough peer review

- Inclusion in PubMed and all major indexing services

- Maximum visibility for your research

Submit your manuscript at www.biomedcentral.com/submit

) Biomed Central 